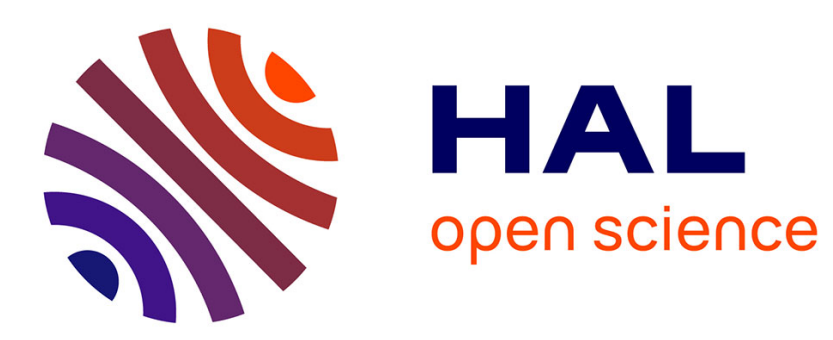

\title{
High Purity Chromium Metal Oxygen Distribution (Determined by XPS and EPMA)
}

\author{
K. Suzuki, H. Tomioka
}

\section{To cite this version:}

K. Suzuki, H. Tomioka. High Purity Chromium Metal Oxygen Distribution (Determined by XPS and EPMA). Journal de Physique IV Proceedings, 1995, 05 (C7), pp.C7-211-C7-216. 10.1051/jp4:1995723 . jpa-00254016

\section{HAL Id: jpa-00254016 https://hal.science/jpa-00254016}

Submitted on 1 Jan 1995

HAL is a multi-disciplinary open access archive for the deposit and dissemination of scientific research documents, whether they are published or not. The documents may come from teaching and research institutions in France or abroad, or from public or private research centers.
L'archive ouverte pluridisciplinaire HAL, est destinée au dépôt et à la diffusion de documents scientifiques de niveau recherche, publiés ou non, émanant des établissements d'enseignement et de recherche français ou étrangers, des laboratoires publics ou privés. 


\title{
High Purity Chromium Metal Oxygen Distribution (Determined by XPS and EPMA)
}

\author{
K. Suzuki and H. Tomioka*
}

Japan Metals and Chemicals Co., Ltd., 8-4 Koami-cho, Nihon-bashi, Chuo-ku, Tokyo 103, Japan

* Japan Metals and Chemicals (USA), Inc., One Innovation Drive, P.O. Box 12138, Research Triangle

Park, NC 27709, U.S.A.

\begin{abstract}
The surface composition of ultra high purity chromium metal and chromium metal produced with conventional $\mathrm{Cr}^{+3}$ electrolyte was investigated via XPS. The distribution and formation of oxide in the matrix of chromium metal was also investigated via SEM. The results are discussed in terms of major elemental surface peaks for virgin material and after argon ion etching. It is demonstrated that the oxygen in ultra high purity chromium metal predominantly exists as a surface phenomenon in the form of $\mathrm{Cr}_{2} \mathrm{O}_{3}$ and the thickness of the oxide layer is a function of the production method.
\end{abstract}

\section{INTRODUCTION}

JMC (USA), Inc. produces ultra high purity chromium metal via electrolysis in their Research Triangle Park, North Carolina, USA facility. Product purity, based on metallic elements, ranges from $99.995 \%$ to 99.999\% chromium providing the highest purity commercial production in the world. The oxygen content of this product ranges from $100 \mathrm{ppm}$ to $300 \mathrm{ppm}$. Although oxygen is the primary elemental impurity, we have little information about its distribution and structure. The purpose of this study was to investigate the structure and distribution of oxygen in high purity chromium metal products.

The surface composition of JMC's ultra high purity chromium metal and chromium metal produced with conventional $\mathrm{Cr}^{+3}$ electrolyte were investigated via XPS (X-ray Photo-electron Spectroscopy) to determine the surface structure. The distribution and formation of oxide in the matrices of these chromium metal products were investigated via SEM (Secondary Electron Microscope). The shape and size of chromium oxide particles were determined by SEM after extracting the chromium metal matrix leaving the chromium oxide particles.

\section{ANALYSIS AND OBSERVATION PROCEDURE}

\subsection{Analysis for Trace Impurities}

The metallic impurities were determined by GDMS (Glow Discharge Mass Spectroscopy) and ICP (Inductively Coupled Plasma Atomic Emission Spectroscopy). Oxygen, nitrogen, carbon and sulfur were analyzed by the Leco method (infrared absorption spectroscopy).

\subsection{XPS Analysis}

High purity chromium metal is harvested from the electrolysis tank in the form of irregular flakes 2 to 3 $\mathrm{mm}$ thick. The flake surface was investigated by XPS utilizing a $\mathrm{Mg} \mathrm{K} \alpha \mathrm{X}$-ray source. Virgin flake 
surfaces were prepared by rinsing with deionized water. The surface of the specimen was argon ion etched $\left(2 \mathrm{kV}, 30 \mathrm{~mA}, 4 \times 10^{-4} \mathrm{~Pa}\right)$ for collecting depth profile data. The specimens of other grades of chromium metal were prepared in the same manner.

\subsection{SEM Observation}

The chromium oxide particle specimens were prepared for SEM observation by dissolving the chromium metal matrix with hydrochloric acid and extracting the oxide particles by filtering.

The chromium metal flakes were heat treated at $1250^{\circ} \mathrm{C}$ for 6 hours in a conventional vacuum furnace to investigate the influence of heat treatment on oxygen distribution and the shape of the oxide particles.

\section{RESULT AND DISCUSSION}

\subsection{Chemical Analysis of the Chromium Metal Samples}

The chemical analysis for the chromium metal flake samples investigated in this study is shown in Table 1. In this table, $4 \mathrm{~N} 5 \mathrm{Cr}$ is the flake produced in JMC's facility in North Carolina, USA. The metallic elements were determined by GDMS. Other elements including oxygen, nitrogen, hydrogen, carbon and sulfur are determined by the Leco method.

As shown in this table, metallic impurity levels in 4N5 Cr are extremely low. Most of them are less than $1 \mathrm{ppm}$ with a few exceptions. Oxygen, at $180 \mathrm{ppm}$, is the primary impurity in this material. Carbon and sulfur are extremely low compared to other commercial chromium metals.

$2 \mathrm{~N}$ is a typical commercial grade chromium metal flake. Compared with $4 \mathrm{~N} 5 \mathrm{Cr}$, oxygen and other impurity levels are much higher. The iron level is about $1000 \mathrm{ppm}$ indicating the existence of significant levels of other metallic impurities.

Table 1: Chemical Analysis for Chromium Metal Flakes

\begin{tabular}{|c|c|c|c|c|}
\hline \multirow[t]{2}{*}{ Sample Name } & \multicolumn{2}{|l|}{$4 \mathrm{~N} 5 \mathrm{Cr}$} & \multicolumn{2}{|l|}{$2 \mathrm{~N} \mathrm{Cr}$} \\
\hline & $\begin{array}{l}\text { Analytical } \\
\text { Data }\end{array}$ & $\begin{array}{l}\text { Analytical } \\
\text { Method }\end{array}$ & $\begin{array}{l}\text { Analytical } \\
\text { Data }\end{array}$ & $\begin{array}{l}\text { Analytical } \\
\text { Method }\end{array}$ \\
\hline Cr Purity (\%) & $99.9995^{*}$ & & $99.38 * *$ & \\
\hline $\mathrm{Al}$ (ppm) & 0.02 & GDMS & 9 & ICP \\
\hline $\mathrm{Si}$ (ppm) & 0.06 & GDMS & 4 & ICP \\
\hline$P(p p m)$ & 0.01 & GDMS & 12 & ICP \\
\hline $\mathrm{Fe}(\mathrm{ppm})$ & 0.06 & GDMS & 850 & ICP \\
\hline $\mathrm{Cu}(\mathrm{ppm})$ & 0.02 & GDMS & 10 & ICP \\
\hline $\mathrm{Pb}(\mathrm{ppm})$ & 1.1 & GDMS & 11 & ICP \\
\hline $\mathrm{C}(\mathrm{ppm})$ & 10 & LECO & 60 & $\overline{\mathrm{LECO}}$ \\
\hline$S(p p m)$ & 1 & LECO & 220 & LECO \\
\hline $\mathrm{N}(\mathrm{ppm})$ & 10 & LECO & 300 & LECO \\
\hline $\mathrm{O}(\mathrm{ppm})$ & 180 & LECO & 4700 & LECO \\
\hline
\end{tabular}

* Based on metallic element

** Total purity 


\subsection{XPS analysis (Determination of the surface structure)}

Figures 1 and 2 show the change in XPS profile for the surfaces of 4N5 $\mathrm{Cr}$ and $2 \mathrm{~N} \mathrm{Cr}$ flake, respectively, as a function of argon ion etching time (shown on the vertical axis). In preparation for these analyses, the specimens were only rinsed with deionized water and were not cleaned by any other chemical or physical cleaning method.

Figure 1 depicts the XPS profile for $\mathrm{Cr} 2 \mathrm{p}$ spectra for the $4 \mathrm{~N} 5 \mathrm{Cr}$ specimen. The 0 minute spectra shows the virgin surface. A close examination of the spectra shows small $\mathrm{Cr}_{2} \mathrm{O}_{3}$ peaks and metallic chromium peaks. After two minutes of argon ion etching, the $\mathrm{Cr}_{2} \mathrm{O}_{3}$ peaks disappear leaving only metallic chromium peaks. No significant change in these spectra is observed after 4 minutes of argon ion etching. This result indicates that the surface oxide layer is extremely thin; we estimate the thickness of the oxide layer to be $10 \mathrm{~nm}$ or less.

Although this figure does not show the complete range of binding energy, chromium and oxygen are observed as main peaks and other metallic elements are not evident.

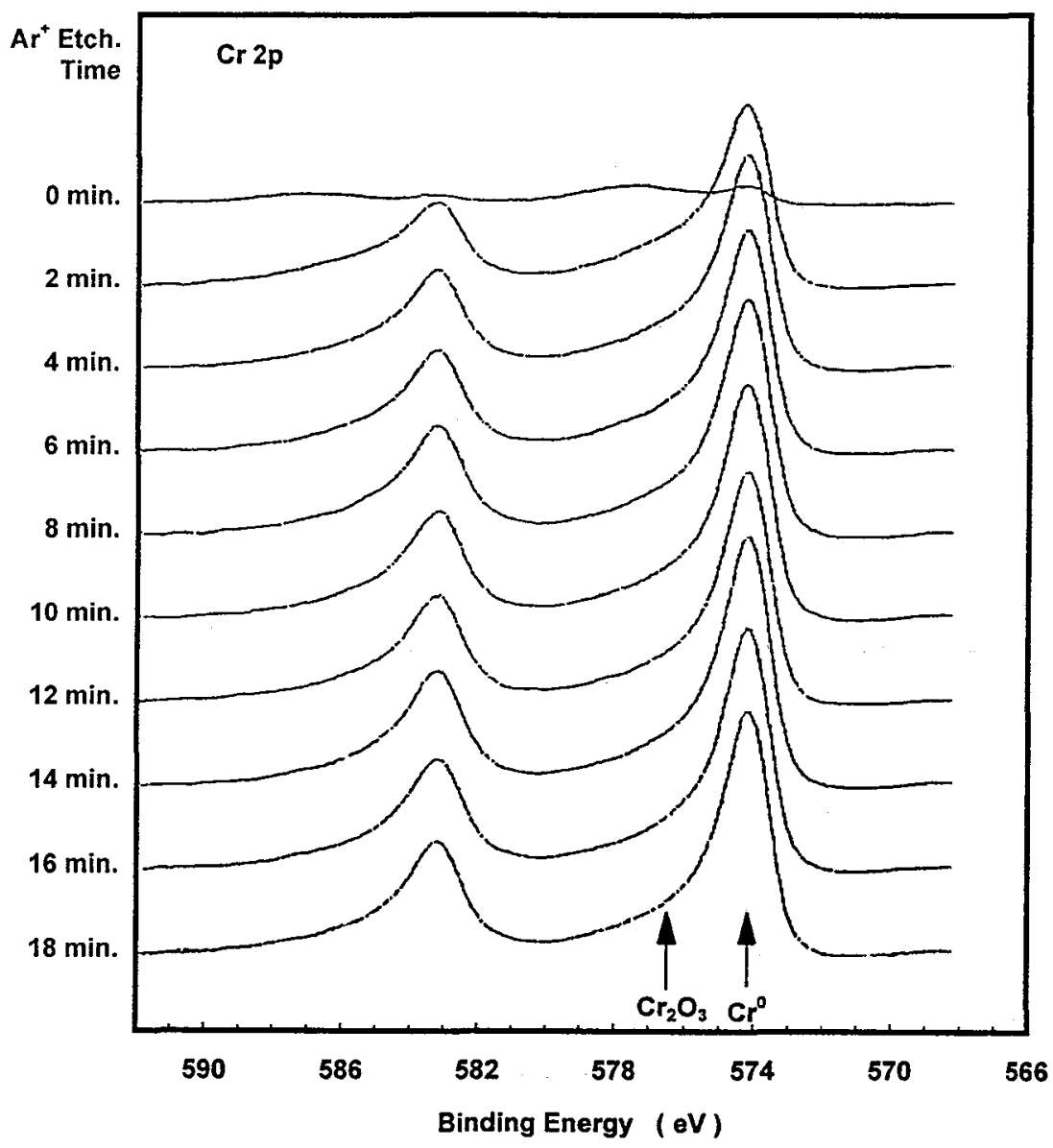

Figure 1: The change in XPS profile for the surfaces of 4N5 Cr flake as a function of argon ion etching time 
Figure 2 shows the XPS profile for the surface of $2 \mathrm{~N} \mathrm{Cr}$ flake. In this figure, conspicuous peaks of $\mathrm{Cr}_{2} \mathrm{O}_{3}$ are found and they remain relatively constant throughout the complete range of argon ion etching time. Please note that the virgin surface data is slightly different indicating surface contamination. Although it is not shown in this figure, the magnitude of the oxygen peak is not changed by extending the argon ion etching time. The oxygen binding energy corresponds to the $\mathrm{Cr}_{2} \mathrm{O}_{3}$ state which supports the premise that the surface $\mathrm{Cr}_{2} \mathrm{O}_{3}$ layer is much thicker than that observed in the $4 \mathrm{~N} 5 \mathrm{Cr}$ specimen.

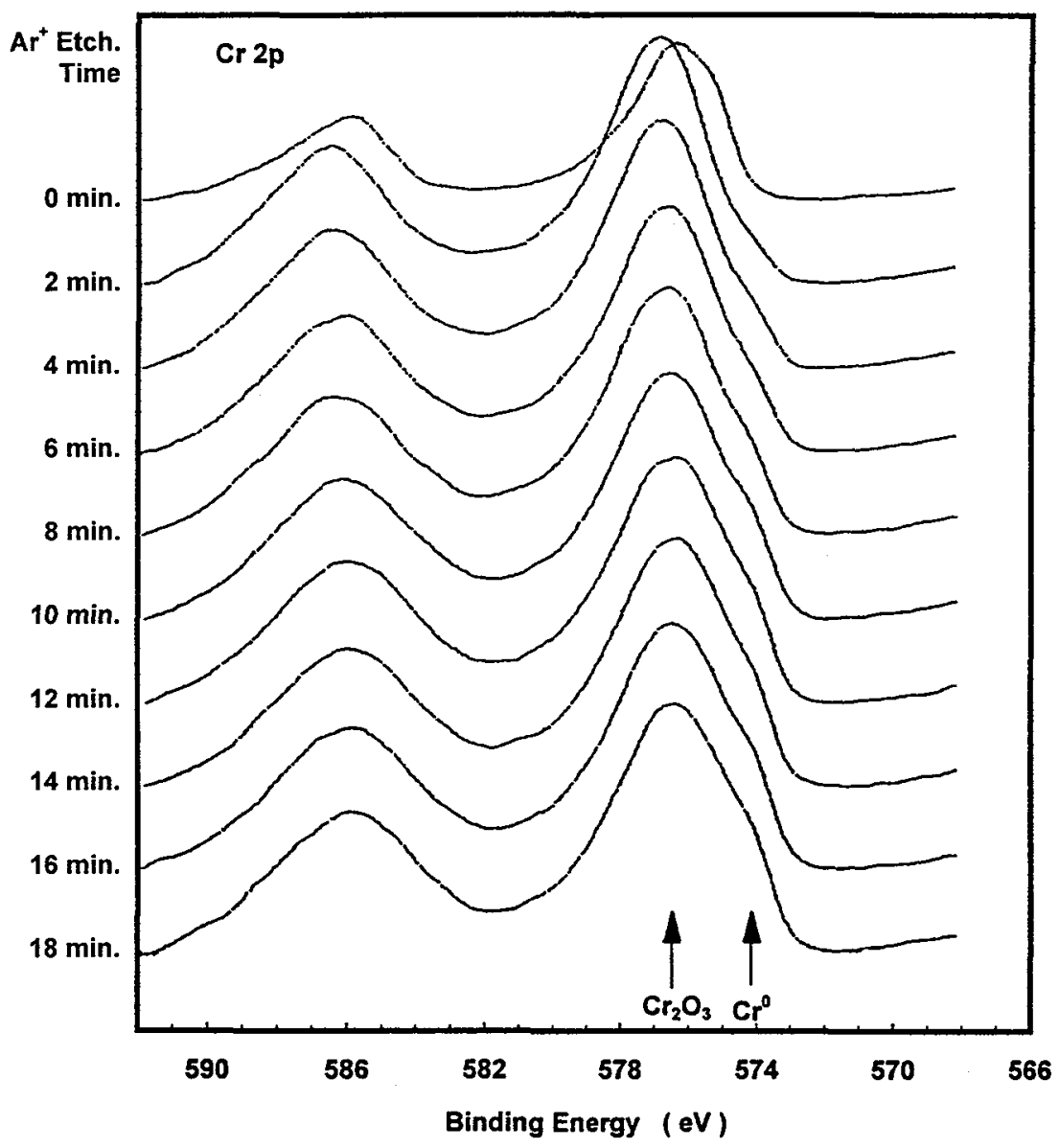

Figure 2: The change in XPS profile for the surfaces of $2 \mathrm{~N} \mathrm{Cr}$ flake as a function of argon ion etching time

\subsection{SEM Observation (Structure of oxide particle in the flake matrices)}

Figure 3 shows results of the SEM observation of extracted $\mathrm{Cr}_{2} \mathrm{O}_{3}$ particles from $4 \mathrm{~N} 5 \mathrm{Cr}$ flake before and after heat treatment. The material was heat treated to determine the influence of heat treatment on oxygen distribution and oxide shape. Figure 3-a shows the specimen without heat treatment. Please note that no extracted $\mathrm{Cr}_{2} \mathrm{O}_{3}$ particles were found in this specimen; the pattern observed is the shape of the filter 
media used for extraction. Figure 3-b shows the specimen after heat treatment. The irregularly shaped particles in this figure are $\mathrm{Cr}_{2} \mathrm{O}_{3}$ particles. This extracted powder was identified as $\mathrm{Cr}_{2} \mathrm{O}_{3}$ by $\mathrm{X}$-ray diffractometry. Also, extracted powder exhibited the greenish color characteristic of $\mathrm{Cr}_{2} \mathrm{O}_{3}$.

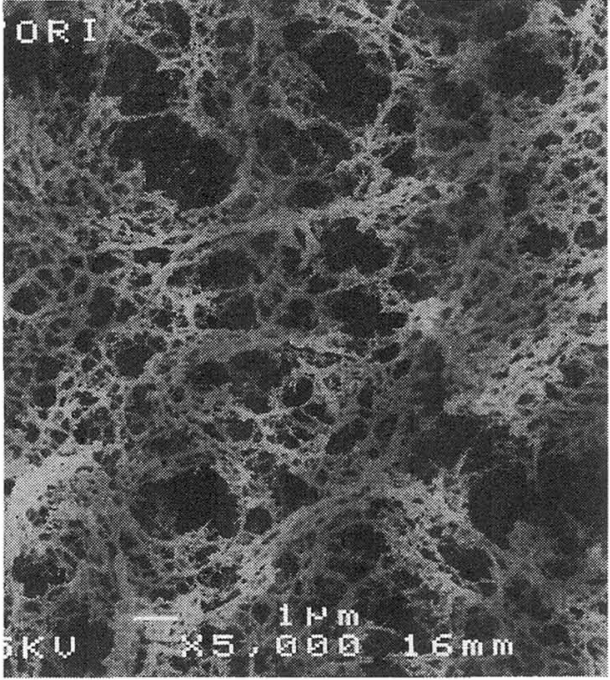

a) without heat treatment

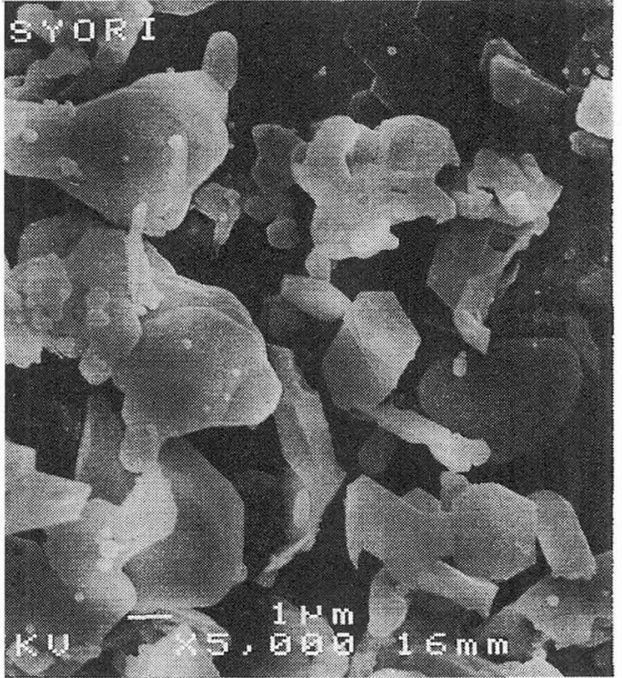

b) after heat treatment

Figure 3: The SEM observation of extracted $\mathrm{Cr}_{2} \mathrm{O}_{3}$ particles from $4 \mathrm{~N} 5 \mathrm{Cr}$

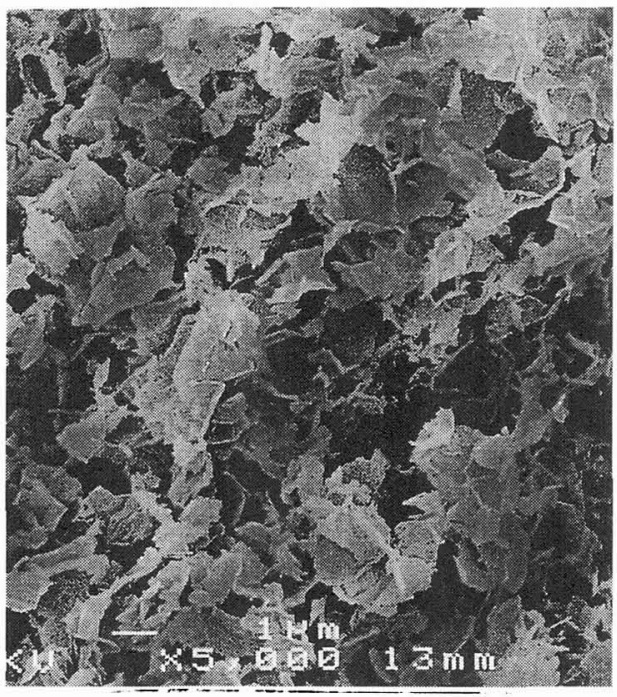

a) without heat treatment
$5 \mu \mathrm{m}$

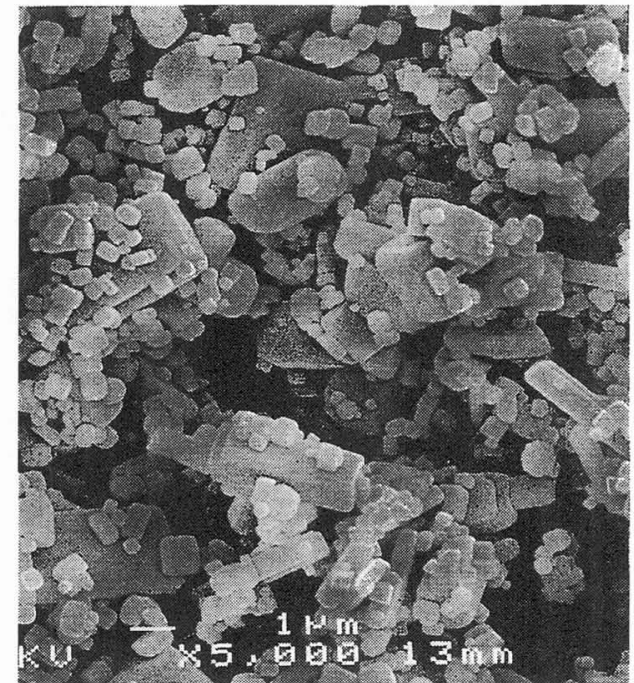

b) after heat treatment

Figure 4: The SEM observation of extracted $\mathrm{Cr}_{2} \mathrm{O}_{3}$ particles from $2 \mathrm{~N} \mathrm{Cr}$ 
The oxygen in high purity chromium metal flake without heat treatment exists in a form of chromium oxide that may be readily dissolved in hydrochloric acid. After heat treatment, the oxygen is converted to the insoluble $\mathrm{Cr}_{2} \mathrm{O}_{3}$ oxide as observed in Figure 3-b.

Figure 4 shows the result of the same investigation for the $2 \mathrm{~N} \mathrm{Cr}$ specimen. Extracted chromium oxide particles are observed in this specimen prior to heat treatment, possibly because of the relatively high oxygen content. We assume that the oxide in the flake without heat treatment exists mainly in the grain boundaries of the metallic chromium matrix because the shape of the extracted oxide appears to be the grain boundary structure with the grains removed. After heat treatment, the shape of the extracted oxide particles becomes a rectangular parallelepiped with slightly rounded corners.

\section{CONCLUSION AND FUTURE INVESTIGATIONS}

\subsection{Conclusion}

The results of our initial study of the structure and distribution of oxygen in high purity chromium metal may be summarized as follows:

(1) The surface oxide layer of ultra high purity chromium metal is extremely thin versus conventional grades of chromium metal produced by electrolysis.

(2) Oxygen in virgin ultra high purity chromium metal flake matrix exists as an oxide which is soluble in hydrochloric acid. After heat treatment, the oxygen is converted to the insoluble $\mathrm{Cr}_{2} \mathrm{O}_{3}$ oxide.

(3) The oxide in conventional grades of chromium metal flake without heat treatment predominantly exists in the grain boundaries of the metallic chromium matrix.

\subsection{Future Investigations}

Data indicates that the corrosion resistance of chromium metal is a function of the purity of the material, i.e. the corrosion resistance increases with increasing purity. These data imply that the integrity of the protective passivation film depends on either the absence or presence of certain impurities. We plan to explore this phenomenon with the following investigations:

- Investigate the structure of potentiostatic passivation films for various grades of chromium metal.

- Investigate the relationship between integrity of protective passivation films and chromium metal impurity levels.

- Investigate purification methods using $4 \mathrm{~N} 5 \mathrm{Cr}$ as a starting material. 